\title{
O IMPACTO DA INSTITUCIONALIZAÇÃO NA INFÂNCIA E NA ADOLESCÊNCIA: UMA REVISÃO DE LITERATURA
}

\author{
Aline Cardoso Siqueira \\ Débora Dalbosco Dell'Aglio \\ Universidade Federal do Rio Grande do Sul
}

\begin{abstract}
RESUMO: Este artigo apresenta uma revisão de literatura sobre as instituições de abrigo, discutindo sua influência no desenvolvimento de crianças e adolescentes. A partir da Teoria Ecológica do Desenvolvimento Humano e do Estatuto da Criança e do Adolescente, foram considerados estudos sobre abrigamento, realizados ao longo das últimas décadas. Muitos estudos discutem a vivência institucional, sendo que alguns apontam prejuízos ao desenvolvimento, enquanto outros indicam que a instituição pode ser uma alternativa positiva, quando o ambiente familiar é desorganizado e caótico. Embora sejam observadas melhoras na qualidade da assistência oferecidas pelos abrigos, especialmente após o ECA, discute-se a necessidade de ações direcionadas às equipes das instituições, a fim de oportunizar melhores condições de trabalho e diminuição da rotatividade. Além disso, é necessário entender a instituição como parte da rede de apoio social e afetivo, que também pode oferecer um espaço para o desenvolvimento saudável de crianças e adolescentes.
\end{abstract} PALAVRAS-CHAVE: institucionalização; crianças; adolescentes; desenvolvimento.

\section{THE IMPACT OF INSTITUTIONALIZATION ON CHILDHOOD AND ADOLESCENCE: A LITERATURE REVIEW}

\begin{abstract}
This article reviews the literature about the impact of shelter institutions on children and adolescents' development. From a theoretical foundation based on the Ecology of Human Development and the views expressed in the Child and Adolescent's Statute, we searched for research conducted over the past few decades on the impact of shelters. Many researchers discuss institutional life, with some of them discussing its damage to development and others indicating its positive features, particularly when the family environment is disorganized and chaotic. Although progress was observed in the quality of the assistance offered by shelters, especially following passage of the Child and Adolescent's Statute, we discuss proposals aimed at institutions' staff, focusing on improving working conditions and decreasing turnover. In addition, it is necessary to understand those institutions as part of the social and emotional support network, and thus an important space for the healthy development of children and adolescents.
\end{abstract}

KEYWORDS: institutionalization; children; adolescents; development.

A problemática da institucionalização na infância e na adolescência, por estar presente na realidade de muitas famílias brasileiras em condições socioeconômicas desfavorecidas, representa uma dimensão relevante de estudo na atualidade. O Levantamento Nacional de Abrigos para Crianças e Adolescentes (Silva, 2004) encontrou cerca de 20 mil crianças e adolescentes vivendo em 589 abrigos pesquisados no Brasil, sendo na sua maioria meninos entre as idades de 7 e 15 anos, negros e pobres. Os dados mostraram ainda que $87 \%$ das crianças e adolescentes abrigados têm família, sendo que 58\% mantêm vínculo com seus familiares. No entanto, foi também constatado que o tempo de duração da institucionalização pode variar até um período de mais de 10 anos. Os efeitos de um período de institucionalização prolongado têm sido apontados na literatura, por interferirem na sociabilidade e na manutenção de vínculos afetivos na vida adulta. Para Carvalho (2002), o ambiente institucional não se constitui no melhor ambiente de desenvolvimento, pois o atendimento padronizado, o alto índice de criança por cuidador, a falta de atividades planejadas e a fragilidade das redes de apoio social e afetivo são alguns dos aspectos relacionados aos prejuízos que a vivência institucional pode operar no indivíduo. Entretanto, outros estudos apontam as oportunidades oferecidas pelo atendimento em uma instituição, salientando que, em casos de situações ainda mais adversas na família, a instituição pode ser a melhor saída (Dell'Aglio, 2000). Assim, a partir dos pressupostos teóricos da Teoria Ecológica do Desenvolvimento Humano (TEDH) (Bronfenbrenner, 1979/ 1996), e de considerações sobre o Estatuto da Criança e do Adolescente (ECA, 1990), busca-se discutir a influência das instituições de abrigo sobre o desenvolvimento de crianças e adolescentes, compreendendo-as como um elemento constituinte da rede de apoio.

\section{Teoria Ecológica do Desenvolvimento Humano}

A abordagem ecológica, proposta por Bronfenbrenner (1979/1996), tem sido usada para reconhecer os processos evolutivos e os múltiplos fatores que influenciam o desenvolvimento humano. Investigar ecologicamente o desenvolvimento de crianças e adolescentes institucionalizados significa entendê-los como "pessoas em desenvolvimento" e considerar este desenvolvimento "no-contexto" (Bron- 
fenbrenner, 1979/1996). A teoria ecológica possibilita que as particularidades desenvolvimentais vivenciadas pelas crianças e pelos adolescentes, que se desenvolvem neste contexto diferenciado, sejam enfatizadas, e não os déficits encontrados em função da comparação com crianças e adolescentes que se desenvolvem em contextos culturalmente esperados (Santana, 2003). Nesta abordagem, o indivíduo está em interação bidirecional, dinâmica e constante com o ambiente.

O ambiente ecológico é entendido por Bronfenbrenner (1979/1996) como um sistema de estruturas agrupadas, independentes e dinâmicas. O primeiro nível está relacionado ao efeito de influências proximais, ambientais e organísmicas, que advém do interior do indivíduo, de suas características físicas e de objetos do ambiente imediato, que caracterizam a relação face a face. Segundo Bronfenbrenner (1979/1996), este nível mais internoé chamado de microssistema, e deve ser entendido para além da família, estendendo-se para outros contextos. As crianças e os adolescentes que vivem em instituição de abrigo têm na própria instituição o microssistema central de seu ambiente ecológico (Yunes, Miranda \& Cuello, 2004). O mesossistema refere-se aos elos e aos processos entre dois ou mais ambientes, nos quais os indivíduos se desenvolvem, isto é, a interação entre os diversos microssistemas. Desta forma, o mesossistema das crianças e dos adolescentes abrigados consiste nas interações entre o próprio abrigo e a sua família de origem, entre a escola e o abrigo, como também entre a família de origem e seus parentes, vizinhos, um programa social no qual a família participa, entre outros. O microssistema e o mesossistema representam os ambientes cujos níveis de relação são proximais e suas influências são mais evidentes, sendo de crucial importância para os processos desenvolvimentais. Aqueles ambientes nos quais o indivíduo não participa diretamente, mas recebe influência indireta, estão em seu exossistema. Assim, a direção da instituição, o Conselho Tutelar e o Conselho Municipal dos Direitos de crianças e adolescentes, por exemplo, são instâncias que podem constituir o exossistema de crianças e adolescentes abrigados (Santana, 2003). Além disso, o mesossistema e o exossistema, a partir de suas dinâmicas de funcionamento, irão influenciar na vida e nas relações destas crianças e adolescentes, sendo fundamental a comunicação e a integração destes ambientes (Miranda, Adorno, Cuello \& Yunes, 2003). O macrossistema, por sua vez, é o sistema mais amplo, abrange os valores, as ideologias e a organização das instituições sociais comuns a uma determinada cultura. No que tange à institucionalização, o estigma social, carregado de valor pejorativo e depreciativo, associado aos valores culturalmente esperados podem ser considerados elementos integrantes do macrossistema que envolve estas crianças e adolescentes. Estes elementos estão presentes no modo como os monitores da instituição lidam com eles, no modo como a professora ensina a criança abrigada, ou ainda, na forma como uma adolescente que vive em instituição relaciona-se com outra adolescente que vive com sua família. Segundo Santana (2003), é essencial que o pesquisador considere o macrossistema, para que ele possa compreender a rede de significações apresentadas pela população em estudo, no que tange à complexa vivência institucional. Assim, o macrossistema é influenciado pelos seus contextos específicos, no caso o cotidiano institucional, e também pelo contexto mais amplo, como os valores culturais. Somente a partir da compreensão destes complexos sistemas e das interações entre eles será possível entender o desenvolvimento humano e, especialmente, o das crianças e adolescentes que vivem em instituição de abrigo.

As diferentes configurações dos microssistemas formam a rede de apoio social, importantes pelo seu efeito moderador no desenvolvimento. A rede de apoio social e afetivo da criança é constituída por tios, avós, primos, além do grupo familiar. Além disso, seus vizinhos, seus amigos e colegas, e também um posto de saúde, um abrigo ou algum programa social da comunidade podem constituir a rede de apoio. A influência será positiva se estes vínculos reforçarem o sentido de eficácia pessoal, caso contrário, seu efeito será evidente no comportamento desadaptado (Hoppe, 1998).

A família é o primeiro microssistema com o qual a pessoa em desenvolvimento interage. Para Bronfenbrenner (1979/1996, 1986), a família é considerada um sistema dinâmico e em interação, compreendida em um ambiente, próximo e imediato, da pessoa em desenvolvimento, que envolve atividades, papéis e um complexo de relações interpessoais. A introdução de aspectos físicos, sociais e simbólicos na sua estrutura contribui para o desenvolvimento dos processos proximais. $\mathrm{Na}$ atualidade, a abordagem ecológica atribui papel central aos processos proximais, nos quais as diferentes formas de interação entre as pessoas são vistas como uma função do processo. Assim, os processos proximais são definidos como as formas particulares de interação entre o organismo e o ambiente, cada vez mais complexas, que operam ao longo do tempo, sendo os principais motores do desenvolvimento (Bronfenbrenner \& Morris, 1998).

Segundo Yunes et al. (2004), tendo em vista a história pregressa das crianças e dos adolescentes abrigados, a institucionalização pode ou não constituir um risco para o desenvolvimento. Esta condição dependerá dos mecanismos através dos quais os processos de risco operarão seus efeitos negativos sobre eles, sendo o risco entendido como as condições ou variáveis que estão associadas a uma alta possibilidade de ocorrência de resultados negativos ou não desejáveis (Jessor, Van Den Boss, Vanderryn, Costa \& Turbin, 1995). Em contrapartida, inúmeros fatores de proteção podem operar neste momento. Os fatores de proteção correspondem às influências que modificam, melhoram ou alteram a resposta dos indivíduos a ambientes hostis 
que predispõem a conseqüências mal adaptativas (Hutz, Koller \& Bandeira, 1996). Entretanto, deve-se compreender o conceito de fatores de proteção enfatizando-se uma abordagem de processos, através dos quais diferentes fatores interagem entre si e alteram a trajetória da pessoa, podendo produzir uma experiência estressora ou protetora em seus efeitos (Morais \& Koller, 2004).

As estruturas interpessoais, tais como as formas de interação no abrigo, estão alicerçadas sob três características de interação: a reciprocidade, o equilíbrio de poder e a relação afetiva (Bronfenbrenner, 1979/1996). Estas características ajudam o microssistema a manter-se estruturado a fim de permitir o desenvolvimento saudável. A reciprocidade está centrada no processo proximal que ocorre entre duas ou mais pessoas. Com seu feedback mútuo, ela gera um momento próprio que os motiva a perseverarem e a se engajarem em padrões de interação subseqüentemente mais complexos (Bronfenbrenner, 1979/1996). Assim, é preciso incentivar as relações recíprocas nos abrigos, visto que incrementam os processos proximais. Entretanto, mesmo havendo reciprocidade, um dos integrantes da relação pode ser mais influente do que o outro. O equilíbrio de poder se refere à distribuição deste poder na relação. É importante o estabelecimento do equilíbrio de poder porque (1) ajuda a pessoa em desenvolvimento a aprender a conceitualizar e a lidar com relações de poder diferenciais; e porque (2) uma situação ótima para a aprendizagem e desenvolvimento é aquela em que o equilíbrio do poder gradualmente é alterado em favor da pessoa em desenvolvimento (Bronfenbrenner, 1979/1996). No ambiente institucional, por exemplo, os diretores e os monitores devem possuir mais poder do que os adolescentes, embora esta distribuição deva ser alterada gradativamente com o amadurecimento destes últimos. A relação afetiva é estabelecida no envolvimento em interações diádicas, possibilitando o desenvolvimento de sentimentos de uns para os outros, podendo ser mutuamente positivos, negativos, ambivalentes ou assimétricos (Bronfenbrenner, 1979/1996). Na medida em que as relações afetivas são positivas e recíprocas no início, sendo cada vez mais positivas, é possível que incrementem o ritmo e a ocorrência dos processos desenvolvimentais. Desta forma, as instituições de abrigo devem considerar o afeto presente nas relações entre seus integrantes, tanto entre as crianças e adolescentes quanto entre estes e seus monitores. A dimensão afetiva é parte inerente das relações humanas, não devendo, portanto, ser excluída enquanto elemento propiciador de desenvolvimento.

A instituição de abrigo consiste em um ambiente ecológico de extrema importância para crianças e adolescentes institucionalizados, configurando o microssistema onde eles realizam um grande número de atividades, funções e interações, como também um ambiente com potencial para o desenvolvimento de relações recíprocas, de equilíbrio de poder e de afeto. Yunes et al. (2004) adaptaram as proposições essenciais para o desenvolvimento positivo, apresentadas por Bronfenbrenner (1990), descritas como processos que podem favorecer o desenvolvimento da competência e do caráter. A primeira proposição está relacionada à necessidade de a criança participar de atividades recíprocas, progressivamente mais complexas, com uma ou mais pessoas, de forma regular. A segunda proposição está centrada na consolidação dos padrões interacionais mencionados na primeira proposição, destacando a importância do apego forte e mútuo, que aumentará o repertório de respostas da criança, convidando-a à exploração do ambiente imediato físico, social e simbólico. A terceira proposição enfatiza a disponibilidade e o envolvimento de adultos que também se engajem na atividade. A quarta proposição destaca a troca de informações, numa comunicação em via dupla, e a quinta proposição salienta os aspectos macrossistêmicos. Assim, as políticas públicas e as práticas sociais e educativas devem partir do reconhecimento dos aspectos macrossistêmicos relacionados à vivência institucional, de forma a tentar desestigmatizá-los, desenvolvendo ações não só direcionadas aos pais ou educadores das instituições, mas a todos os membros da sociedade (professores, profissionais da saúde, amigos, parentes, órgãos econômicos, sociais e políticos). Estas proposições inovam ao focalizar as características das relações interpessoais e afetivas como elementos essenciais no microssistema, os quais estão diretamente relacionados ao desenvolvimento saudável dos indivíduos. Além disso, os processos proximais estão presentes em cada uma destas proposições, podendo influenciar a trajetória de vida das crianças, de forma a inibir ou incentivar a expressão de competências cognitivas, sociais e emocionais. Estes processos são considerados ativadores do desenvolvimento psicológico, sendo que a simples ausência de interações com um ou mais adultos, que queiram o bem incondicional destas crianças e adolescentes, que estão sob seus cuidados, pode configurar em uma ameaça ao desenvolvimento psicológico sadio (Yunes et al., 2004).

\section{Instituições de Abrigo e ECA: uma revisão histórica}

Bronfenbrenner (1979/1996) contemplou a institucionalização em seus estudos, compreendendo que uma instituição de atendimento infantil pode servir como contexto abrangente para o desenvolvimento humano. Para ele, duas hipóteses acerca do ambiente institucional são importantes: a primeira se refere a um aumento do prejuízo quando o meio ambiente oferece poucas possibilidades de interação cuidador-criança e quando existe uma restrição quanto às oportunidades de locomoção e brincadeiras espontâneas; e a segunda hipótese focaliza o impacto disruptivo imediato, quando a separação das crianças ocorre na segunda metade do primeiro ano de vida. Desta maneira, as reações nocivas, a longo prazo, de um meio ambiente institucional, físico e socialmente empobrecido, diminuem com o au- 
mento da idade da criança na entrada à instituição, e com a presença de um leque de atividades que possibilite engajamento.

Apesar de ser um contexto possível de desenvolvimento, a instituição não fornece um equivalente funcional familiar para seus internos (Bronfenbrenner, 1979/1996). Além disso, outros autores destacam que em certos lares, o meio ambiente físico e social é tão empobrecido e caótico que a colocação de uma criança em uma instituição pode proporcionar a recuperação e um crescimento psicológico (Clarke \& Clarke, 1976, citados em Bronfenbrenner, 1979/1996). Sendo assim, torna-se importante analisar historicamente os estudos acerca da institucionalização, a fim de compreender melhor os fatores presentes neste contexto.

Estudos mais antigos (Bowlby, 1973/1998; Goldfarb, 1943, 1945, citados em Grusec \& Lytton, 1988) apontaram os prejuízos cognitivos que a vivência institucional proporcionava para as crianças abrigadas, tal como déficit intelectual, especialmente no desenvolvimento da linguagem. Estas crianças eram mais distraídas e agressivas, apresentando dificuldades emocionais, de comportamento e incapacidade de formar laços afetivos duráveis com outros. Embora estes estudos convergissem ao apontar os prejuízos ocasionados pela vivência institucional, Grusec e Lytton (1988) problematizaram estes resultados, considerando que estes efeitos poderiam surgir de outros fatores. Segundo estes autores, estudos posteriores confirmaram que, de fato, muitas crianças, que viveram os primeiros anos de vida em abrigo, apresentaram problemas de aprendizagem e também má adaptação social. Entretanto, é provável que a ausência de estimulação e de oportunidades de brincadeiras, encontradas em instituições pobres da década de 40, e a ausência de estrutura emocional familiar tenham contribuído para agravar este panorama.

Estudos apontam mudanças nas práticas de cuidados direcionados às crianças e aos adolescentes abrigados, ao longo do tempo. Por exemplo, no final da década de 1970, já existiam abrigos residenciais de alta qualidade, na Inglaterra, nas quais cada unidade era composta por seis crianças, que tinham acesso a brinquedos, livros e também a uma proporção cuidador/criança generosa. O sistema destas unidades se assemelhava ao sistema familiar (Grusec \& Lytton, 1988). O estudo de Tizard, Cooperman, Joseph e Tizard (1972) investigou o efeito da qualidade do trabalho dos monitores e o desenvolvimento do nível da linguagem das crianças institucionalizadas, nestes abrigos residenciais. Este estudo apontou que o atraso intelectual não estava necessariamente relacionado à vivência institucional. O nível ótimo de desenvolvimento da linguagem foi relacionado à qualidade da conversa do cuidador, e não à frequiência de conversações iniciadas pelo mesmo. Além disso, os cuidadores com maior autonomia tendiam a brincar e a conversar mais com as crianças, levando-as a um melhor escore na avaliação do desenvolvimento da linguagem. Assim, foi possível observar que os efeitos prejudiciais da entrada em instituição, nos primeiros anos de vida, existiam, contudo estavam sendo demasiadamente enfatizados.

Segundo Grusec e Lytton (1988), os fatores que modificam os efeitos dos cuidados em instituição de abrigo são de origem multifatorial, sendo estes efeitos não uniformes ou fixos. Os fatores são: (1) motivo da separação da criança e sua família; (2) qualidade da relação prévia com a mãe; (3) oportunidade para desenvolver relações de apego depois da separação; (4) qualidade do cuidado na instituição; (5) idade da criança e duração da separação; e (6) também o sexo e o temperamento da criança. Bowlby (1973/1998), por sua vez, destaca duas condições de maior importância no que tange à diminuição das reações negativas frente à separação de crianças e suas mães: a primeira está relacionada à presença de uma pessoa conhecida e/ou de objetos familiares no novo ambiente de desenvolvimento da criança; e a segunda, à presença de cuidados maternais de uma mãe substituta. Desta forma, os efeitos danosos da separação são mínimos quando estas duas condições estão associadas.

Assim, Grusec e Lytton (1988) propõem duas questõeschave no que tange à institucionalização: (1) os efeitos danosos advêm da privação de estimulação necessária para o desenvolvimento ou da privação do cuidado materno? E (2) estes efeitos surgem do rompimento dos vínculos de apego ou de distúrbios das relações familiares? Quanto à primeira questão, muitos déficits intelectuais, observados em instituições de abrigo, podem ser devido a privações de algum tipo de estimulação sensorial, independente do cuidado materno. De qualquer forma, mesmo em instituições de alta qualidade, a inteligência e autonomia de crianças deste contexto são marcadamente menores do que aquelas que foram cuidadas em suas casas. Isto sugere que a segurança emocional, derivada da existência de relações estáveis na vida da criança, pode contribuir para o funcionamento intelectual adequado. Quanto à segunda questão, muitos dos problemas de conduta de crianças abrigadas já estavam presentes antes da institucionalização. Isto aponta para os fatores de risco no ambiente familiar, onde as relações eram marcadamente instáveis, estressantes e conflituosas. Assim, estas experiências precoces demonstraram operar um papel importante no desenvolvimento posterior, e, desta forma, a separação em si não constituiu o fator decisivo.

No Brasil, historicamente, a política de atendimento à infância e à juventude em situação de abandono vem sofrendo transformações. O gerenciamento e a implantação destas políticas de atendimento saiu, gradativamente, do domínio da Igreja, passando por profissionais filantropos, até ser de responsabilidade do estado, como é nos tempos atuais. No Brasil Colonial, o abandono de crianças foi uma prática encontrada entre índios, brancos e negros (Leite, 
1997). Da mesma forma, Priore (1991/1996) afirmou que o abandono de bebês, a vida em abrigos e as violências cotidianas (abusos sexuais e físicos, por exemplo) foram características da infância no Brasil por mais de três séculos.

Uma das mais duradouras instituições de assistência à infância, vinculada à Igreja, foi a roda dos expostos, prática que tinha como objetivo recolher crianças abandonadas anonimamente (Marcilio, 1997). Criada no período do Brasil Colônia, a roda dos expostos atravessou e multiplicou-se no período imperial, conseguindo manter-se durante a República e só foi extinta definitivamente em 1950. Durante mais de um século, a roda de expostos foi praticamente a única instituição de assistência à criança abandonada em todo o Brasil. Algumas vezes, famílias substitutas acolhiam estes bebês, seja pelo espírito de caridade, ou mesmo com a intenção de transformá-los em mão-de-obra familiar fiel, reconhecida e gratuita, na juventude e na adultez. Marcilio (1997) afirma que a prática de criar filhos alheios sempre, e em todos os tempos, foi difundida e aceita no Brasil. Ainda hoje, esta prática está fortemente integrada à sociedade (Fonseca, 1987, 1993, 1995).

A partir de 1860, inúmeras instituições de proteção à infância desamparada surgiram no Brasil, como estabelecimentos de abrigo e de educação para menores "desvalidos", de caráter público ou privado. A menina foi essencialmente protegida, devido à preservação da honra e da castidade. Inaugurou-se uma nova fase do assistencialismo no Brasil: a filantropia, surgindo como um modelo capacitado para substituir o modelo representado pela caridade, vinculada à Igreja (Marcilio, 1997; Rizzini, 1990). A filantropia organizou a assistência dentro das novas exigências sociais, políticas, econômicas e morais, que nasceram com o início do século XX no Brasil, juntamente com a República.

Segundo Freitas (1997), o advento da República ensejou uma revalorização da infância, uma vez que o imaginário republicano reiterava de várias formas a imagem da criança como herdeira do novo regime que se estabelecia. Entretanto, a problemática do menor republicano no Brasil, vítima de violência e de abandono, somente passou a ser enfrentada em meados dos anos de 1970, principalmente através de denúncias regulares contra esta situação (Passetti, 1991/1996). Desta forma, foi com a indicação de 1978 como o "Ano Internacional da Criança" que a história da criança no Brasil começou a ser focalizada e pesquisada. Este fato levou à formação de diversas associações, que se articularam a outras, na defesa dos direitos da criança e que acabaram influenciando na elaboração do Estatuto da Criança e do Adolescente de 1990. Desta forma, foi durante a vigência do século XX que um modo mais humano de lidar com a infância e com a juventude abandonada passou a existir, juntamente com uma real preocupação quanto à situação psicossocial dos mesmos.
A partir do Estatuto da Criança e do Adolescente (ECA, 1990), as crianças e os adolescentes passam de objetos de tutela a sujeitos de direitos e deveres. Contudo, Santana (2003) destacou que o movimento social que deu origem ao ECA, ainda que tenha contado com a participação da sociedade civil, em termos de representatividade social, deixou a desejar. Desta forma, foi possível perceber que a noção de criança e adolescente como sujeitos ainda não estava compartilhada por grande parte da sociedade. Este fato ainda hoje pode ser observado, especialmente em relação às crianças e aos adolescentes em situação de rua, sendo muitas vezes exigidas, do poder público, soluções enérgicas contra os mesmos, geralmente no sentido de punilos, sem a intenção de garantir seus direitos (Santana, 2003). Para que os dispositivos do ECA sejam cumpridos, de acordo com Silva (2004), é necessário que tanto os responsáveis por sua aplicação quanto os executores, tenham não apenas amplo conhecimento do estatuto mas também partilhem seus objetivos, contribuindo para que efetivamente as crianças e adolescentes possam exercer plenamente seus direitos.

Entre os diretos previstos pelo ECA (1990), destacase o direito à convivência familiar e comunitária, que prevê o fim do isolamento, presente na institucionalização em décadas anteriores (Rizzini \& Rizzini, 2004; Silva, 2004). OECA também preconiza a desinstitucionalização no atendimento de crianças e adolescentes em situação de abandono e valoriza o papel da família, as ações locais e as parcerias no desenvolvimento de atividades de atenção, trazendo mudanças no panorama do funcionamento das instituições de abrigo. Assim, as instituições de abrigo devem estar configuradas em unidades pequenas, com poucos integrantes, manter um atendimento personalizado, estimular a participação em atividades comunitárias e preservar o grupo de irmãos, entre outros pontos. A implantação do ECA contribuiu para mudanças efetivas no que tange às instituições de assistência e à sua configuração como um todo, partindo não de uma visão puramente assistencialista, mas concebendo-as como espaço de socialização e de desenvolvimento. Quanto às condições dos atuais abrigos, Silva (2004) sinaliza que, dentre os abrigos pesquisados da Rede SAC, (1) cerca de 56,7\% foram considerados de pequeno porte, atendendo até 25 abrigados; (2) em geral, possuem as condições físicas, de abastecimento de luz, saneamento e esgoto adequados; (3) 56\% mantêm salas para atendimento técnico especializado; (4) possuem dirigentes mulheres $(60,4 \%)$ com ensino superior completo $(60,8 \%)$, entre outros aspectos. Entretanto, há diferenças evidentes entre as regiões brasileiras. Por exemplo, a região norte destacou-se por possuir $92 \%$ de seus abrigos com no máximo 25 crianças e adolescentes, e a região Centro-Oeste ficou no último lugar, com 58,5\% dos seus abrigos atendendo pequenos grupos. Na região Sul, $27 \%$ dos dirigentes dos abrigos são pós-graduados e na região Norte, $12 \%$. É possível observar diferenças significativas entre o perfil 
apresentado neste levantamento e o modelo das instituições mais antigas, visto que esta nova configuração difere qualitativamente daquelas, nas quais havia um grande número de crianças e adolescentes vivendo sob um sistema essencialmente coletivizado (Guirado, 1986).

Ainda que o programa de abrigo esteja previsto pelo ECA (1990) como medida provisória e transitória, a permanência breve ou continuada no abrigo está inteiramente relacionada à história singular de cada criança e/ou adolescente. Desta forma, a promoção de ações efetivas de inserção social se constitui em um objetivo permanente, para que o abrigo seja realmente uma medida protetiva de caráter excepcional e transitório (ECA, 1990). Para Juliano (2005), os fatores que dificultam a efetivação do caráter provisório da medida de abrigo são: (1) a falta de integração das políticas sociais existentes; (2) a dificuldade de interação e comunicação entre as entidades que trabalham com crianças e adolescentes em situação de risco pessoal e social; (3) a ausência de objetivos comuns entre estas entidades; (4) a existência de ações pontuais e fragmentadas; (5) a fragilidade dos recursos humanos nos abrigos, tanto na quantidade como na sua qualificação; (6) como, também, a fragilidade das famílias, que se posicionam passivamente frente às ações que poderiam resultar no desabrigamento de seus filhos. De fato, para muitos casos, a passagem por uma instituição de abrigo não é temporária, sendo que muitas crianças e adolescentes ficam durante anos nestas instituições sem a possibilidade de estarem em famílias substitutas, ou ainda, sem poderem voltar para suas famílias de origem. Além disso, na prática, os abrigos demonstram fragilidade em seu funcionamento (Arpini, 2003; Bazon $\&$ Biasoli-Alves, 2000). Atualmente, a comunidade científica voltou-se ainda mais a este ambiente social, investigando inúmeros elementos que compõem este contexto, desde as questões sobre o seu funcionamento, até aquelas referentes ao desenvolvimento sadio de seus integrantes, suas percepções de família, da vivência institucional, entre outros.

\section{Estudos recentes sobre abrigos no Brasil}

O estudo de Yunes, Miranda, Cuello e Adorno (2002) sobre abrigos apontou a predominância da função assistencialista nos mesmos, fundada na perspectiva tão somente de ajudar as crianças abandonadas, havendo um frágil compromisso com as questões desenvolvimentais da infância e da adolescência. Além disso, são observados problemas funcionais, como, por exemplo, o número de funcionários inadequado, ocasionando dificuldade no cumprimento das funções, sobrecarga das tarefas e um atendimento pouco eficaz; e a precariedade na comunicação dentro do microssistema institucional (funcionário/diretoria do abrigo, adolescentes/funcionário, entre outros) e, sobretudo entre os microssistemas (abrigo/escola, abrigo/Conselho Tutelar, abrigo/outra instituição que a criança ou adolescente fre- qüenta, entre outros), refletindo dificuldades de articulação na rede de apoio social.

Pasian e Jacquemin (1999) desenvolveram um estudo que investigou a auto-imagem, através do auto-retrato gráfico, em crianças institucionalizadas e não-institucionalizadas, de 7 a 13 anos. Os resultados indicaram que as crianças que viviam em abrigos apresentaram maior número de indicadores emocionais em seus desenhos, na comparação com as crianças que viviam com suas famílias. Em contrapartida, o tempo de institucionalização configurou-se um fator importante, visto que aquelas crianças com mais tempo no abrigo apresentaram elementos de uma auto-imagem mais integrada. Assim, segundo Pasian e Jacquemin, foi possível afirmar que o tempo de contato da criança com uma estrutura institucional, propiciadora de experiências de vida positivas, pode favorecer a diminuição do número de sinais de dificuldades emocionais. Já o estudo desenvolvido por Martins e Szymanski (2004) buscou investigar a percepção de família de crianças em instituição de abrigo, a partir da análise da brincadeira de faz-de-conta, empreendida por elas. Dentre os resultados, destaca-se que a cooperação, ou ajuda mútua, permeou a grande maioria das interações. As crianças se organizaram dentro dos papéis familiares, cooperando com a organização da casa e auxiliando umas as outras em diversos momentos. Outro resultado interessante foi a referência predominante ao modelo de família nuclear, apesar de suas famílias de origem não possuírem esta forma de configuração, apontando para a forte influência dos valores culturais macrossistêmicos.

Dell'Aglio (2000) investigou diversos aspectos no desenvolvimento de crianças e adolescentes que viviam em instituições de abrigo e que viviam com a família, não tendo encontrado diferenças consistentes entre os grupos. As análises apontaram resultados semelhantes no nível intelectual, desempenho escolar, estratégias de coping e estilo atribucional, tendo sido encontrada diferença somente nos índices de depressão, que foram mais altos entre as meninas institucionalizadas. No entanto, conforme Dell' Aglio (2000), este resultado não pode ser interpretado como indicação de que haja alguma relação causal entre institucionalização e depressão. Na maioria dos casos a institucionalização se deu em conseqüência de eventos traumáticos na família (abandono, violência doméstica, negligência), podendo ter sido este o principal fator de risco para a depressão. Além disso, a autora também aponta que, para muitos dos participantes de seu estudo, a institucionalização foi percebida como um evento de vida positivo.

O estudo de Arpini (2003), desenvolvido com adolescentes de classes populares, também observou que aqueles que tiveram vivência institucional a caracterizavam como o melhor período de suas vidas, relacionando-a com o estabelecimento de novos vínculos, alguns dos quais se mantiveram mesmo após deixarem a instituição. Em contrapartida, estes adolescentes demonstraram sofrer um forte estigma 
social, pois são vistos pela sociedade como responsáveis e donos de algum tipo de "defeito" ou problema (Altoé, 1993; Arpini, 2003). Assim, se por um lado existe uma representação mais positiva em relação à vivência institucional, por outro, permanece a representação social que estigmatiza as pessoas que compõem este contexto (Arpini, 2003). Ao estudar a representação que o ex-interno, na maioridade, faz do período que passou abrigado, em instituição de grande porte e com funcionamento coletivizado, Altoé (1990) constatou que o relato foi marcado por ambivalências: uma idealização associada a duras críticas relacionadas às vivências negativas, tais como a falta de carinho e a falta de liberdade para conversar com outros internos e/ou com os funcionários.

Um outro estudo investigou o perfil dos presidiários egressos de estabelecimentos de assistência à criança e ao adolescente (Altoé, 1993). No que tange ao abrigamento, cabe ressaltar que apenas $24,5 \%$ dos participantes estiveram em instituição de abrigo por mais de um ano, sendo considerados, no estudo, como "jovens institucionalizados". Estes jovens ingressaram no abrigo com idade entre 0 e 8 anos, e o principal motivo de abrigamento foi a falta de condições financeiras da família. Os "jovens não-institucionalizados", 75,5\% da amostra de presidiários, eram jovens com trajetórias instáveis de vida, com diversas passagens por inúmeros abrigos, com duração menor de um ano. Estes jovens ingressaram no abrigo com idade entre 9 e 18 anos, tendo com principal motivo de entrada a realização de atos infracionais (Altoé, 1993). Se por um lado estes resultados apontam para a ineficiência da rede de assistência à infância e à juventude em situação de risco pessoal e social, por outro lado, aqueles jovens que conseguiram permanecer mais tempo no abrigo, aproveitando melhor os recursos oferecidos, cometeram menos delitos e/ou crimes após os 18 anos. No entanto, Silva (1997) enfatiza o aspecto negativo da institucionalização, apontando que o processo de socialização que se dá nos abrigos, pela interação com grupos de risco e pela utilização de mecanismos de resistência, contribui para a construção de uma "identidade institucional", a qual evoluirá para uma "identidade delinqüente", consolidada pela reincidência e pela multirreincidência. Neste sentido, para Bronfenbrenner (1979/1996) ser criado em abrigos, do ponto de vista de valores e expectativas culturais, está associado a um estigma que pode se tornar uma predição de fracasso. Desta forma, as instituições de abrigo podem ou não produzir efeitos benéficos para a vida de crianças e adolescentes, dependendo de sua capacidade de fornecer apoio e proteção.

\section{A Instituição como Rede de Apoio Social e Afetivo}

Para Samuelsson, Thernlund e Ringström (1996) a rede de apoio social tem uma profunda influência na saúde e no bem-estar do indivíduo. A rede de apoio social e afe- tivo define como o indivíduo percebe seu mundo social, como se orienta nele, suas estratégias e competências para estabelecer relações, como também os recursos que este lhe oportuniza frente às situações adversas que se apresentam. A ausência de uma rede de apoio social pode produzir um senso de solidão e falta de significado de vida (Samuelsson et al., 1996).

O efeito protetivo que o apoio social oferece está relacionado ao desenvolvimento da capacidade de enfrentamento de adversidades, promovendo características de resiliência e desenvolvimento adaptativo (Brito \& Koller, 1999; Garmezy \& Masten, 1994; Rutter, 1987). Cada esfera da vida, tais como família, amigos, profissão, vizinhos, escola, instituição de abrigo, entre outros, assume o papel de identidade social capaz de fornecer apoio nas relações que o indivíduo estabelece com os outros. Quanto mais percebe com satisfação sua rede de apoio, mais sentimentos de satisfação com sua vida terá (Orford, 1992). Dessa forma, pode-se compreender que, para as crianças e os adolescentes abrigados, a instituição de abrigo se constitui na fonte de apoio social mais próxima e organizada, desempenhando um papel fundamental para o seu desenvolvimento.

Para Newcomb (1990), a primeira relação de apoio social evolui das relações de apego iniciais da criança e da capacidade e disposição dos pais em suprir suas necessidades, constituindo a primeira base de esperança e segurança em outras pessoas. Para as crianças e os adolescentes que não vivem com suas famílias, o mundo social expandese ainda mais no momento em que estes deixam o núcleo familiar, incluindo membros não pertencentes à família, tais como monitores e demais crianças e adolescentes com os quais convivem na instituição.

A relação estabelecida com os monitores desempenha papel central na vida das crianças e dos adolescentes abrigados, à medida que serão estes adultos que assumirão o papel de orientá-los e protegê-los, constituindo, neste momento, os seus modelos identificatórios. Estudos apontam para a importância de cursos de formação, oficinas de reciclagem, ou mesmo um espaço de trocas destinado a estes profissionais, visto que a satisfação profissional está diretamente relacionada à qualidade de seu trabalho na instituição (Bazon \& Biasoli-Alves, 2000). Estas autoras consideraram os monitores como educadores, e desta forma, apontaram a necessidade de que sejam guiados em suas ações cotidianas de modo a compreender o impacto que seus gestos podem ter, a fim de darem um sentido às suas ações rotineiras.

Da mesma forma, o contato com pares, em igual situação de vida, pode configurar um apoio social e afetivo, operando como fator de proteção. Ao conviver com crianças e adolescentes de diversas idades, as crianças e adolescentes abrigados podem se envolver em parcerias uns com 
os outros, compartilhar sentimentos positivos e negativos, apoiando-se mutuamente. Martins e Szymanski (2004) apontaram que comportamentos pró-sociais, como de cuidado recíproco, consolo e auxílio, em várias situações de vida, foram observados nas interações entre as crianças cuidadas em instituição de abrigo.

\section{Considerações Finais}

A partir dos estudos apresentados, é possível constatar que as instituições de abrigo fazem parte da rede de apoio de muitas famílias brasileiras, há muitas décadas, principalmente em decorrência de problemas sociais, associados à situação de pobreza e ao perfil de distribuição de renda no Brasil. Estes aspectos macrossistêmicos precisam ser combatidos, através de políticas públicas, visto que incrementam a vulnerabilidade das famílias, aumentando a demanda desta população por instituições de abrigo para assistência a seus filhos.

Da mesma forma, a análise de estudos mais recentes possibilita constatar uma melhora na qualidade da assistência oferecida pelos abrigos (Arpini, 2003; Dell'Aglio, 2000; Martins \& Szymanski, 2004; Pasian \& Jacquemin, 1999), sendo que estas melhorias estão diretamente relacionadas à construção e à implementação do ECA (1990) no Brasil (Rizzini \& Rizzini, 2004; Silva, 2004). É possível, também, compreender que estas melhorias refletem um modo diferenciado de avaliar o espaço institucional, especialmente com a consideração de teorias que focalizam o "desenvolvimento-no-contexto" e os aspectos protetivos e de risco presentes nele. A partir destes dados, podese concluir que a visão exclusivamente prejudicial dos abrigos, como lugares insalubres e precários, onde um grande número de crianças e adolescentes convivia sob um sistema coletivizado, vem perdendo força.

Uma vez que a instituição de abrigo é necessária, é preciso que ela seja de pequeno porte, assegure a individualidade de seus integrantes e possua uma estrutura material e de funcionários adequadas. É necessário transformá-la num ambiente de desenvolvimento, capacitando-a e instrumentalizando-a. Para tanto, Yunes et al. (2004) sugerem as seguintes ações: (1) promover um programa lúdico de atividades para as crianças e os adolescentes abrigados junto com os funcionários, o que incentivaria os cuidadores a desenvolver brincadeiras infantis; (2) oportunizar encontros entre os profissionais de diferentes abrigos, a fim de criar um espaço de troca de experiência e melhorar a comunicação interinstitucional; (3) capacitar profissionalmente os cuidadores, para que eles possam aprender sobre desenvolvimento infantil numa visão contextualizada, sobre as práticas educativas, sobre a violência doméstica, sobre as medidas socioeducativas e também para que eles possam compreender as teorias implícitas que permeiam o ambiente institucional.
Para Silva (2004), os profissionais das entidades que oferecem programas de abrigo têm um importante papel de educadores, o que requer uma profissionalização da área e uma política de recursos humanos que envolva capacitação permanente, incentivos e valorização, incluindo uma remuneração adequada. A formação continuada desta equipe deve buscar, ainda, a formação de uma consciência social em prol do bem-estar desta população, considerando que o trabalho institucional traz repercussões diretamente relacionadas ao desenvolvimento das crianças e adolescentes abrigados (Bazon \& Biasoli-Alves, 2000; Yunes et al., 2004). Além disso, acrescenta-se um trabalho organizacional de valorização do funcionário e/ou monitor dos abrigos, de forma que não seja um ofício temporário e rotativo. A efetivação destas ações contribuiria para uma autovalorização do funcionário e/ou monitor, e conseqüentemente, diminuiria a possibilidade de rompimento constante de vínculos.

As discussões sobre a qualidade do atendimento e os prejuízos que os abrigos proporcionam para o desenvolvimento estão longe de convergirem, indicando a necessidade de desenvolver mais estudos sobre os processos presentes neste contexto. Apesar das melhorias observadas no atendimento, há um caminho a ser percorrido. Pode-se começar por oportunizar condições que pelo menos reduzam os fatores de risco já vivenciados nos seus ambientes de origem, sistematizar uma maior integração e comunicação em via dupla dentro dos abrigos e entre as entidades sociais e promover relações interpessoais recíprocas, afetivas e com equilíbrio de poder.

As instituições assumem o lugar central na vida das crianças e dos adolescentes abrigados, e em função disso, é necessário investir neste espaço de socialização, buscando transformar as concepções socialmente estabelecidas, de forma a desestigmatizá-las. De acordo com a ênfase dada pela Teoria Ecológica aos processos proximais ocorridos em contextos de desenvolvimento (Bronfenbrenner, 1979/1996, 1990; Bronfenbrenner \& Morris, 1998), e sobretudo, de acordo com a importância do afeto mútuo e recíproco das relações interpessoais, torna-se crucial investir em interações mais estáveis e afetuosas no ambiente institucional, tanto as relações dos funcionários com os internos quanto às relações entre pares.

As crianças e os adolescentes institucionalizados precisam interagir efetivamente com pessoas, objetos, símbolos e com um mundo externo acolhedor (Bronfenbrenner, 1990). Assim, o abrigo precisa fazer parte da rede de apoio social e afetivo, fornecendo recursos para o enfrentamento de eventos negativos advindos tanto de suas famílias quanto do mundo externo, modelos identificatórios positivos, segurança e proteção. Somente assim oferecerá um ambiente propício para o pleno desenvolvimento cognitivo, social e afetivo das crianças e adolescentes inseridos neste contexto. Assim, destaca-se a necessidade de políticas públicas 
de intervenção direcionadas às instituições de abrigo, considerando o grande número de crianças e adolescentes abrigados, de forma que se favoreça uma melhoria das condições de atendimento a esta população.

\section{Referências}

Altoé, S. (1990). Internato de menores: educar para (de)formar? Fórum Educacional (Rio de Janeiro), 14, 50-76.

Altoé, S. (1993). Do internato à prisão: quem são os presidiários egressos de estabelecimentos de assistência à criança e ao adolescente? In: Rizzini, I. (Ed.), A criança no Brasil hoje: desafio para o terceiro milênio (pp.213-223). Rio de Janeiro: Editora Universitária Santa Úrsula.

Arpini, D. (2003). Violência e exclusão: Adolescência em grupos populares. São Paulo: EDUSC.

Bazon, M. \& Biasoli-Alves, Z. (2000). A transformação de monitores em educadores: uma questão de desenvolvimento. Psicologia: Reflexão \& Crítica, 13, 199-204.

Bowlby, J. (1981). Cuidados maternos e saúde mental. São Paulo: Martins Fontes. (Original publicado em 1976)

Bowlby, J. (1998). Apego e perda: separação-angústia e raiva. São Paulo: Martins Fontes. (Original publicado em 1973)

Brito, R. \& Koller, S.H. (1999). Desenvolvimento humano e redes de apoio social e afetivo. In: Carvalho, A. (Ed.), O mundo social da criança: natureza e cultura em ação (pp.115-129). São Paulo: Casa do Psicólogo.

Bronfenbrenner, U. (1986). Ecology of the family as a context for human development. Developmental Psychology, 6, 723-742.

Bronfenbrenner, U. (1990). Discovering what families do. In: Blankenhorn, D., Bayme, S. \& Elshtain, J. (Eds.), Rebuilding the nest (pp.27-39). Wisconsin: Family Service America.

Bronfenbrenner, U. (1996). A ecologia do desenvolvimento humano. Porto Alegre: Artes Médicas. (Original publicado em 1979)

Bronfenbrenner, U. \& Morris, P. (1998). The ecology of developmental processes. In: Damon, W. (Ed.), Handbook of child psychology, vol.I, pp.993-1027. New York: John Wiley \& Sons.

Carvalho, A. (2002). Crianças institucionalizadas e desenvolvimento: possibilidades e desafios. In: Lordelo, E., Carvalho, A. \& Koller, S.H. (Eds.), Infância brasileira e contextos de desenvolvimento, vol. I, pp.19-44. São Paulo: Casa do psicólogo.

Dell'Aglio, D.D. (2000). O processo de coping, institucionalização e eventos de vida em crianças e adolescentes. Tese de Doutorado não-publicada, Programa de Pós-graduação em Psicologia do Desenvolvimento, Universidade Federal do Rio Grande do Sul. Porto Alegre, RS.

Estatuto da Criança e do Adolescente (1990). Diário Oficial da União. Lei $n^{\circ} 8069$, de 13 de julho de 1990. Brasília, DF: Palácio do Planalto.

Fonseca, C. (1987). O internato do pobre: Febem e a organização doméstica em um grupo porto-alegrense de baixa renda. Temas IMESC, Sociedade, Direito, Saúde (São Paulo), 4, 21-39.

Fonseca, C. (1993). Criança, família e desigualdade social no Brasil. In: Rizzini, I. (Ed.), A criança no Brasil hoje: desafio para o terceiro milênio (vol.I, pp.113-131). Rio de Janeiro: Editora Universitária Santa Úrsula.

Fonseca, C. (1995). Caminhos da adoção. São Paulo: Cortez.

Freitas, M. (1997). História social da infância no Brasil. São Paulo: Cortez.
Garmezy, N. \& Masten, A. (1994). Chronic adversities. In: Rutter, M., Taylor, E. \& Herson, L. (Eds.), Child and adolescent psychiatry (pp.191-207). Oxford: Blackwell.

Grusec, J.E. \& Lytton, H. (1988). Social development: history, theory and research. New York: Springer-Verlang.

Guirado, M. (1986). Instituição e relações afetivas: o vínculo com o abandono. São Paulo: Summus.

Hoppe, M. (1998). Redes de apoio social e afetivo de crianças em situação de risco. Dissertação de Mestrado não-publicada, Programa de Pós-graduação em Psicologia do Desenvolvimento, Universidade Federal do Rio Grande do Sul. Porto Alegre, RS.

Hutz, C., Koller, S.H. \& Bandeira, D.R. (1996). Resiliência e vulnerabilidade em crianças em situação de risco. Coletâneas $d a$ ANPEPP, 1, 79-86.

Jessor, R., Van Den Boss, J., Vanderryn, J., Costa, F. \& Turbin, M. (1995). Protective factors in adolescent problem behavior: moderator effects and developmental change. Developmental Psychology, 31, 923-933.

Juliano, M. A influência da ecologia dos ambientes de atendimento no desenvolvimento de crianças e adolescentes abrigados. Dissertação de Mestrado emEducação Ambiental não-publicada, Fundação Universidade Federal do Rio Grande. Rio Grande, RS.

Leite, M.M. (1997). A infância no século XIX segundo memórias e livros de viagem. In: Freitas, M. (Ed.), História social da infância no Brasil (pp.17-50). São Paulo: Cortez.

Marcilio, M.L. (1997). A roda dos expostos e a criança abandonada na história do Brasil: 1726-1950. In: Freitas, M. (Ed.), História social da infância no Brasil (pp.51-76). São Paulo: Cortez.

Martins, E. \& Szymanski, H. (2004). Brincando de casinha: significado de família para crianças institucionalizadas. Estudos de Psicologia (Natal), 9, 177-187.

Miranda, A., Adorno, R., Cuello, S. \& Yunes, M.A. (2003). O funcionamento dos abrigos como parte integrante da rede de apoio social na cidade de Rio Grande/RS [Resumo]. In: Sociedade Brasileira de Psicologia do Desenvolvimento (Ed.), Resumos de comunicações científicas, IV Congresso Brasileiro de Psicologia do Desenvolvimento (pp.274-275). João Pessoa: SBPD.

Morais, N.A., Koller, S.H. (2004). Abordagem ecológica do desenvolvimento humano, psicologia positiva e resiliência: ênfase na saúde. In: Koller, S.H. (Ed.), Ecologia do desenvolvimento humano: pesquisa e intervenções no Brasil (pp.91-107). São Paulo: Casa do Psicólogo.

Newcomb, M. (1990). Social support and personal characteristics: a developmental and interactional perspective. Journal of Social and Clinical Psychology, 9, 54-68.

Orford, J. (1992). Community psychology: theory and practice. New York: Wiley.

Pasian, S. \& Jacquemin, A. (1999). O auto-retrato em crianças institucionalizadas. Paidéia, 9, 50-60.

Passetti, E. (1996). O menor no Brasil Republicano. In: Priore, M. (1996), História da criança no Brasil (pp.146-175). São Paulo: Contexto. (Original publicado em 1991)

Priore, M.D. (1996). O papel branco, a infância e os jesuítas na Colônia. In: Priore, M. (Ed.), História da criança no Brasil (pp.1027). São Paulo: Contexto (Original publicado em 1991)

Rizzini, I. (1990). A assistência à infância na passagem para o século XX: da repressão à reeducação. Fórum Educacional, 14, 77-95.

Rizzini, I. \& Rizzini, I. (2004). A institucionalização de crianças no Brasil. Rio de Janeiro: Ed. PUC-Rio.

Rutter, M. (1987). Psychosocial resilience and protective mechanisms. American Journal Orthopsychiatry, 57, 316-331. 
Siqueira, A.C. \& Dell'Aglio, D.D. "O Impacto da Institucionalização na Infância e na Adolescência: Uma Revisão de Literatura"

Samuelsson, M., Thernlund, G. \& Ringström, J. (1996). Using the five map to describe the social network of children: a methodological study. International Journal Behavioral Development, 19,327-345.

Santana, J.P. (2003). Instituições de atendimento a crianças e adolescentes em situação de rua: objetivos atribuídos por seus dirigentes e pelos jovens atendidos. Dissertação de Mestrado nãopublicada, Programa de Pós-graduação em Psicologia do Desenvolvimento, Universidade Federal do Rio Grande do Sul. Porto Alegre, RS.

Silva, E.R. (2004). O direito à convivência familiar e comunitária: Os abrigos para crianças e adolescentes no Brasil. Brasília: IPEA/ CONANDA.

Silva, R. (1997). Os filhos do governo. São Paulo: Ática.

Tizard, B., Cooperman, O., Joseph, A. \& Tizard, J. (1972). Environmental effects on language development: a study of young children in long-stay residential nurseries. Child Development, 43, 337-358.

Yunes, M.A., Miranda, A.T. \& Cuello, S.S. (2004). Um olhar ecológico para os riscos e as oportunidades de desenvolvimento de crianças e adolescentes institucionalizados. In: Koller, S.H. (Ed.), Ecologia do desenvolvimento humano: Pesquisa e intervenções no Brasil (pp.197-218). São Paulo: Casa do Psicólogo.

Yunes, M.A., Miranda, A.T., Cuello, S.S. \& Adorno, R.S. (2000). A história das instituições de abrigo às crianças e concepções de desenvolvimento infantil [Resumo]. In: Sociedade Brasileira de Psicologia (Ed.), Resumos de comunicações científicas, XXXII Reunião Anual da Sociedade Brasileira de Psicologia (pp.213214). Florianópolis: SBP
Aline Cardoso Siqueira é Psicóloga, Mestre e Doutoranda em Psicologia do Desenvolvimento da Universidade Federal do Rio Grande do Sul (UFRGS).

Débora Dalbosco Dell'Aglio é Doutora em Psicologia do Desenvolvimento e Docente no Programa de Pós-

Graduação em Psicologia do Desenvolvimento da Universidade Federal do Rio Grande do Sul (UFRGS). Endereço para correspondência: Instituto de Psicologia, UFRGS, Ramiro Barcelos 2600, 90.035-003, Porto Alegre, RS. dalbosco@cpovo.net

\section{O impacto da institucionalização na infância e na adolescência: uma revisão de literatura}

Aline Cardoso Siqueira e Débora Dalbosco Dell'Aglio Recebido: 14/07/2005

$1^{\text {a }}$ revisão: $12 / 09 / 2005$

Aceite final: 25/11/2005 